\title{
Observation and quantification of in situ animal-sediment relations using time-lapse sediment profile imagery (t-SPI)
}

\author{
Martin Solan*, Robert Kennedy \\ Martin Ryan Marine Science Institute, National University of Ireland, Galway, Galway City, Ireland
}

\begin{abstract}
One of the controlling factors in determining colonisation and survivorship of benthic species is the physical nature of the sediment which, in turn, is regulated by the activities of the resident infauna. This study uses in situ time-lapse sediment profile imagery (t-SPI) to examine the organism-sediment relations of a highly developed benthic assemblage dominated by the ophiuroid Amphiura filiformis. Information related to apparent physical and biological changes in sediment profile structure over two $24 \mathrm{~h}$ periods are quantified. Estimates of burrowing capacity, infaunal spatial arrangement, disc chamber formation, feeding mound construction and feeding periodicity for A. filiformis are presented. The use of t-SPI confirmed that $A$. filiformis is a highly active and dominant member of the infauna. Movie sequences revealed that burrowing and feeding activity greatly influences sediment structure and may mask the bioturbatory activities of other species.
\end{abstract}

KEY WORDS: Sediment Profile Imagery $\cdot$ REMOTS $\cdot$ Amphiura filiformis $\cdot$ Bioturbation $\cdot$ Time-lapse photography

Resale or republication not permitted without written consent of the publisher

\section{INTRODUCTION}

The dynamical and functional aspects of organismsediment relations form the background to many influential benthic ecological opinions and theories. Rosenberg (1976) and Rhoads et al. (1978) demonstrated that benthic assemblages undergo predictable and sequential changes in response to disturbance (i.e. succession), a concept formalised by Pearson \& Rosenberg $(1976,1978)$. Their paradigm describes the predictable and sequential appearance of infauna belonging to specific functional types over time and/or space away from a benthic disturbance (i.e. Stage I, 'pioneering' to Stage III, 'equilibrium' series). These views were, however, formulated upon data that was mostly obtained with grab sampling methods, an approach that has no means of evaluating small-scale structure.

*Present address: OceanLab, University of Aberdeen, Newburgh, Aberdeenshire AB41 6AA, Scotland.

E-mail:m.solan@abdn.ac.uk
Sediment Profile Imagery (SPI) provides a means to witness and quantify, in situ, the net result of animalsediment relations without disrupting the organismsediment couple. This technique incorporates a wedgeshaped imaging module that acts as an inverted periscope that penetrates the seafloor (see Rhoads \& Young 1970, Rhoads \& Cande 1971, Rhoads \& Germano 1982, 1986). An image of the undisturbed sediment profile is digitised and the visible features that may assist in the reconstruction of recent successional history are measured with proprietary software. Although SPI allows the direct observation of the sedimentary matrix, choosing when and how often one should image the benthos depends largely on the objectives of the operator and is influenced by budgetary and time constraints. The use of 'snapshot' SPI observations over extended time intervals (weeks to months) are adequate for long term benthic monitoring and habitat assessment studies, but are of limited use when considering events and/or processes that occur over small time scales (minutes to hours). 
The use of time-lapse photography has shown to be an effective tool for capturing temporal phenomena and has been adopted in an increasing number of applications as equipment has become more sophisticated and readily available (London et al. 1998). In the marine environment, time-lapse cameras have been used mainly in the deep sea to monitor epibenthic faunal behaviour (e.g. Bett \& Rice 1993, Smith et al. 1993, Tyler et al. 1993, Collins et al. 1998), with comparatively fewer studies taking place in shallow coastal and estuarine waters (e.g. Nestlerode \& Diaz 1998). Although these studies have been instrumental in revealing much about the processes and events that take place on or just above the sediment-water interface, few studies (e.g. Diaz \& Cutter in press) have attempted to quantify changes that occur below the sediment water interface. It is reasonable to suggest that net benthic physiological and biogeochemical processes visible in a sediment profile image will reflect recent infaunal activity.

This study uses a combination of SPI and time-lapse photography to make continuous non-destructive in situ observations of an 'equilibrium' assemblage dominated by the ophiuroid Amphiura filiformis. This species has been given 'keystone' status within the assemblage in question on several occasions (e.g. O'Connor et al. 1983), an assumed role based on little empirical data other than its consistent placement as a numerical dominant. The extent to which the presence of Amphiura is responsible for the physico-chemical and biological structure of the sediment profile is of fundamental importance to understanding the long-term stability of the assemblage.

\section{MATERIALS AND METHODS}

A diver-operated sediment profiling camera was deployed on 2 occasions at the Margaretta station $\left(53^{\circ} 13.50^{\prime} \mathrm{N}, 09^{\circ} 6.50^{\prime} \mathrm{W}\right)$ located within the North Bay of Inner Galway Bay, Ireland. This station has previously been recognised as a 'pristine' site of great scientific interest due to the persistence over time of an Amphiura filiformis sub-community, originally described by Keegan et al. (1976) and continually monitored since that time (e.g. O'Connor et al. 1983, 1986a, 1986b, Pagnoni 1999, Kennedy 2000, Solan 2000). Margaretta is located in the centre of the anti-clockwise gyre (Booth 1975, Harte et al. 1982, Lei 1995). It lies in approximately $22 \mathrm{~m}$ of water and mean bottom currents are usually $<25 \mathrm{~cm} \mathrm{~s}^{-1}$ (Keegan et al. 1976). Annual bottom temperatures range from 5.8 to $16.8^{\circ} \mathrm{C}\left(\mathrm{O}^{\prime} \mathrm{Connor}\right.$ et al. 1983) and salinity remains above 33 (Bowmer 1982). The circulation of water around the station forms a central area of net deposition (Ni Cheilachair 1992), a mechanism that has been suggested as an important factor in securing the long-term stability of the resident infaunal assemblage (Pagnoni 1999).

The diver SPI is devoid of the large support frames, hydraulic dampening unit, and adjustable weighting system of larger SPI cameras and consists solely of the imaging module and a small stabilising mud door (Fig. 1). The sediment profile is momentarily illuminated (ca. $25 \mathrm{~ms}$ ) by an internal flash strobe at the point of image capture. This SLR camera system was electronically modified to incorporate an automated interval timing facility (Nikon Multifunction MF-21 camera back) with a user interface that allows the start time,

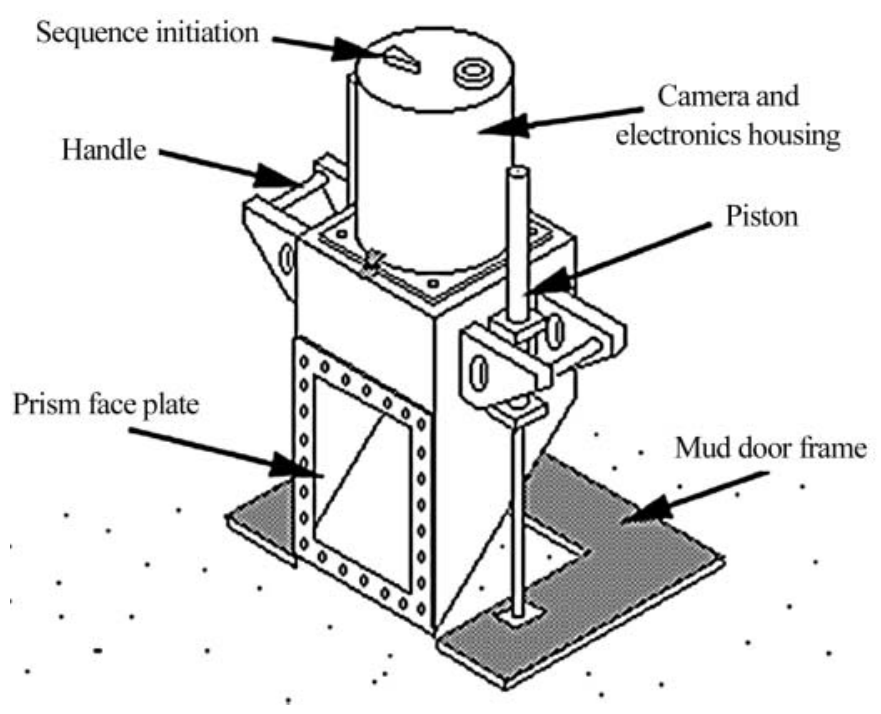

Fig. 1. Diagrammatic representation of the time-lapse SPI unit (t-SPI)

end time, and the timing interval between successive shots to be programmed. The dimensions of the prism face-plate allow a maximum visible profile area of $330 \mathrm{~cm}^{2}(15 \times 22 \mathrm{~cm})$ to be imaged. Photographic slide film (Kodak $35 \mathrm{~mm}$ ektochrome) was manually packed to allow 50 shots per deployment. Each successive shot occurred at an interval of $30 \mathrm{~min}$. Processing and development followed the specific standard operating procedures required for this film type (Kodak, UK).

The first time-lapse SPI sequence (t-SPI) started on a neap high tide (11:41 h BST; Admiralty Tidal charts) on 29 September 1998 and ended at 11:11 h BST on 30 September 1998 (i.e. 23.5 h; 48 shots). The second sequence started on the corresponding spring high tide (18:23 h BST; Admiralty Tidal charts) on 6 October 1998 and ended at 18:23 h BST on 7 October 1998 (i.e. $24.0 \mathrm{~h}$; 49 shots). On each occasion, the t-SPI unit was placed in situ by a team of scuba divers as far in advance of the experiment as harbour traffic restrictions would allow. 
This equated to approximately $2 \mathrm{~h}$ prior to the neap tide sequence. For the spring tide deployment, it was possible to extend this interval to $6 \mathrm{~h}$. The prism face-plate was orientated to face eastwards (before penetration) to minimise hydrodynamic interference at the sedimentwater interface caused by the predominately west-eastwest tidal currents on station. The apparatus was not revisited again until after the experimental period had passed. Weather conditions were calm throughout both experimental periods.

Each slide diapositive was scanned in red-greenblue (RGB) colour at a resolution of 300 dots per inch (DPI) and $640 \times 480$ pixels using an Epson Filmscan 200 slide scanner. Images were saved in the non-compressed tagged image file format (TIFF) for Apple Macintosh in colour and also in 256 grey scales using Photoshop 5.0 (Adobe Inc., USA). The conversion from single frames to a digital Quicktime movie (Apple Inc., USA) was achieved using GraphicConverter 3.5.1 (Lemkesoft GmbH, Germany).

Image interrogation and analysis was performed using Image Analyst 9.0.3 (RVSI Europe Ltd., UK) on all grey scale images. This software interrogates the image at the intensity level, or grey scale value, of individual pixel elements following a scaling calibration. Grey scale analysis was used to determine the intensity level distribution within the region of interest and to determine areas of similar grey scale shades. Connectivity analysis was used to find groups of connected pixels with an intensity value above or below a userdefined threshold value. The areas of geometric and topological features distinguished within a region of interest were automatically calculated using in-built software algorithms. The sediment-water interface was interpolated manually.

Table 1. Listing of the inferred and measured physical, chemical, and biological parameters collated for each t-SPI image

\begin{tabular}{l|l|}
\hline Physical & Biological \\
\cline { 1 - 1 } Min. prism penetration $(\mathrm{cm})$ & No. mud clasts \\
Max. prism penetration $(\mathrm{cm})$ & Epifauna visible \\
Mean prism penetration $(\mathrm{cm})$ & Surface faecal pellet layer \\
Surface boundary roughness & Total no. surface tubes \\
Grain size major (phi) & No. surface tubes $<2 \mathrm{~mm}$ \\
Grain size minimum (phi) & No. surface tubes $>2 \mathrm{~mm}$ \\
Grain size maximum (phi) & No. feeding mounds \\
& No. feeding pits \\
Chemical & Subsurface infauna \\
\hline Area oxic sediment $\left(\mathrm{cm}^{2}\right)$ & No. subsurface burrows \\
Min. aRPD $(\mathrm{cm})$ & Subsurface oxic voids $<5 \mathrm{~cm}$ \\
Max. aRPD $(\mathrm{cm})$ & Subsurface oxic voids $>5 \mathrm{~cm}$ \\
Mean aRPD $(\mathrm{cm})$ & \\
Water column $\mathrm{O}_{2}$ status & \\
Methane bubbles & \\
\hline
\end{tabular}

Twenty-five individual parameters ( 7 physical, 6 chemical, 12 biological; Table 1) were either measured or inferred directly from the images in accordance with standard definitions and methods (see Keegan \& Retière 1987, Diaz \& Schaffner 1988, Solan 2000). Information related to the density, behaviour, and animal-sediment relations of the ophiuroid Amphiura filiformis were estimated from both t-SPI deployments, but not all of the lifestyle traits of this species could be measured simultaneously. From the spring tide occupancy, the apparent spatial positioning of individual excavations (i.e. arm burrows + disc chamber), the apparent rate of burrowing and burrow infill, the apparent periodicity of active feeding behaviour, and the apparent volume of sediment ejected to the surface as feeding mounds were estimated. The apparent maximal size and rate of disc chamber construction was estimated from the neap tides occupancy.

The rate and size of disc chamber formation was estimated by measuring the cross-sectional area of one imaged disc chamber. The volume of the disc chamber void was calculated by assuming that the imaged void was half a sphere against the prism face-plate.

For each Amphiura filiformis excavation (i.e. burrows + disc chamber), the maximum depth, angle from the horizontal, and relative spacing from adjacent excavations were measured. Laboratory observations of $A$. filiformis indicate that mounds associated with feeding activity are approximately conical but do not fully taper. Volume of sediment within each mound (Fig. 2) was calculated as a frustrum of a cone using the formula:

$$
M_{\mathrm{v}}=1 / 3 \pi h\left(R^{2}+R r+r^{2}\right)
$$

where $M_{\mathrm{v}}=$ inferred volume of mound $\left(\mathrm{cm}^{3}\right) ; R=$ radius of base of imaged mound $(\mathrm{cm}) ; r$ radius of top of imaged mound $(\mathrm{cm}) ; h=$ height of imaged mound $(\mathrm{cm})$.

To assess the rate and volume of burrow formation and burrow infill, and to derive an estimation of net burrow formation with time, the relative position of Amphiura filiformis individual G (Fig. 3) and the area and relative position of burrow void was tracked over time. For calculation of burrow volume, the visible burrow void was assumed to be half a cylinder against the camera faceplate. The rate of burrow formation and infilling was assessed by comparing each image to the previous image in the sequence. The estimated apparent burrow volume for Individual $\mathrm{G}$ was combined with the estimate for disc chamber volume to derive an approximate estimation of total burrow surface area $\left(\mathrm{B}_{\mathrm{TSA}}\right)$.

The amount and periodicity of feeding activity in relation to the tidal cycle of the resident population of Amphiura filiformis was estimated by counting the number of visible feeding arms above the sedimentwater interface. 


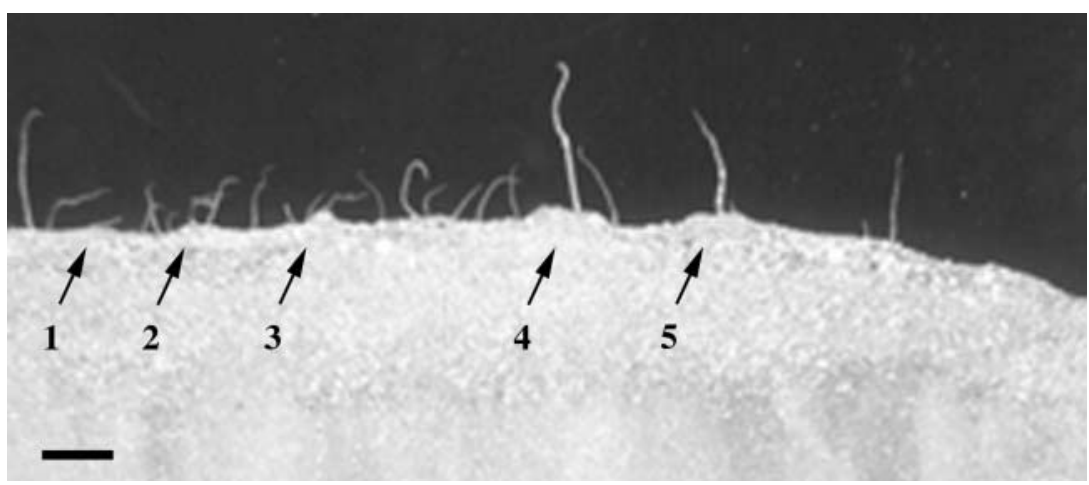

Fig. 2. Amphiura filiformis, feeding mounds. Location along the sediment-water interface and identification codes (1 to 5) assigned to all visible feeding mound structures constructed by $A$. filiformis during the spring tide t-SPI sequence. Scale bar $=1.0 \mathrm{~cm}$

To establish the successional status of the station, measured and inferred SPI parameters were interpreted against the ecological successsional paradigm of Pearson \& Rosenberg (1978). The relative placement of each t-SPI image along this gradient was assigned according to the computed scores of the Organism Sediment Index (OSI) and the Benthic Habitat Quality (BHQ) index (see, inter alia, Rhoads \& Germano 1982, 1986, Valente et al. 1992, Nilsson \& Rosenberg 1997). These indices both adopt the premise that benthic succession results in the predictable appearance of macroinvertebrates belonging to specific functional groups and that these groups reflect overall habitat quality.

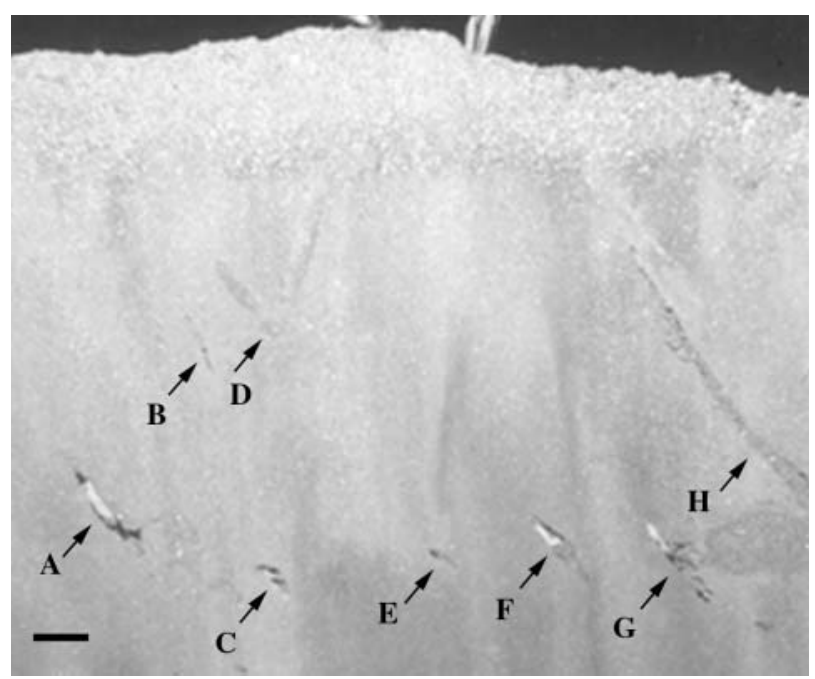

Fig. 3. Amphiura filiformis, excavations. Location within the sediment profile and identification codes (A to $\mathrm{H})$ assigned to all $A$. filiformis excavations (= arm burrows + disc chamber) visible during the spring tide t-SPI sequence. These excavations continually oscillated from these positions throughout the sequence. Scale bar $=1.0 \mathrm{~cm}$
Habitat quality is defined along a continuum relative to the salient physico-chemical and biological features predicted by the Pearson \& Rosenberg (1978) model of succession. Each of these variables is assigned a score and the total index value predicts the infaunal successional stage. The lowest index values are given to those bottoms that lack all surface and subsurface faunal structures and for which the apparent redox potential discontinuity (aRPD) is either absent or very shallow. Similarly, the highest index values are assigned to those bottoms that show quantifiable evidence of extensive infaunal reworking associated with a deep aRPD. The score range can vary from -10 to +11 for the OSI and from 0 to 15 for the BHQ index. To reduce the subjectivity of the OSI successional stage determination, the successional stage computed from the BHQ index was used in place of a user-defined stage. Successional series were attributed using these score values in accordance with the methods outlined in Valente et al. (1992) and Nilsson \& Rosenberg (1997) respectively.

\section{RESULTS}

The physical presence of the camera assembly appeared to have little influence on near bed current flow as minimal erosion or deposition of the sedimentwater interface took place. On both occasions, an unknown number of swimming crabs (Necora puber) aggregated around the t-SPI module and, although no burrowing occurred against the camera face-plate, bouts of activity disturbed the subsurface infauna. Both the neap and spring tide t-SPI occupancies showed evidence of infaunal bioturbatory activity and a corresponding deep aRPD. These factors contributed highly to the successional status of each station. The main faunal element was the ophiuroid Amphiura filiformis. Individuals were observed suspension feeding during successive tidal flows (e.g. Fig. 6), maintaining individual burrow structures, and were located at depths up to several $\mathrm{cm}$.

\section{Short term temporal change}

The physical, chemical, and biological SPI parameters for the neap and spring tide occupancies are summarised in Table 2. These features showed little 
Table 2. Minimum, maximum and mean $( \pm 95 \%$ CI) inferred and measured physical, chemical, and biological parameters for the neap tide (left, $\mathrm{n}=48$ ) and spring tide (right, $\mathrm{n}=49$ ) time-lapse occupancies at Margaretta

\begin{tabular}{|c|c|c|c|c|c|c|c|c|}
\hline \multirow{2}{*}{ Parameter } & \multicolumn{4}{|c|}{ Neap t-SPI } & \multirow[b]{2}{*}{ Minimum } & \multirow{2}{*}{$\begin{array}{l}\text { Spring } \\
\text { Maximum }\end{array}$} & \multirow{2}{*}{$\begin{array}{l}\text { SPI }- \\
\text { Mean }\end{array}$} & \multirow[b]{2}{*}{$95 \% \mathrm{Cl}$} \\
\hline & Minimum & Maximum & Mean & $95 \% \mathrm{CI}$ & & & & \\
\hline Min. prism penetration $(\mathrm{cm})$ & 18.31 & 20.18 & 19.34 & 0.14 & 17.05 & 17.97 & 17.69 & 0.06 \\
\hline Max. prism penetration (cm) & 19.50 & 21.01 & 20.42 & 0.10 & 18.60 & 19.53 & 19.12 & 0.06 \\
\hline Mean prism penetration (cm) & 19.33 & 20.54 & 19.88 & 0.08 & 18.11 & 18.63 & 18.41 & 0.03 \\
\hline Surface boundary roughness & 0.10 & 2.09 & 1.08 & 0.18 & 0.76 & 2.37 & 1.41 & 0.10 \\
\hline Grain size major (phi) & $2-3$ & $2-3$ & $2-3$ & - & $2-3$ & $2-3$ & $2-3$ & - \\
\hline Grain size minimum (phi) & $>4$ & $>4$ & $>4$ & - & $3-4$ & $3-4$ & $3-4$ & - \\
\hline Grain size maximum (phi) & $1-2$ & $1-2$ & $1-2$ & - & $1-2$ & $1-2$ & $1-2$ & - \\
\hline Area oxic sediment $\left(\mathrm{cm}^{2}\right)$ & 95.30 & 116.95 & 107.82 & 1.20 & 113.90 & 131.20 & 125.31 & 1.12 \\
\hline Min. aRPD $(\mathrm{cm})$ & 3.81 & 6.16 & 5.21 & 0.14 & 4.24 & 5.98 & 5.10 & 0.10 \\
\hline Max. aRPD (cm) & 8.52 & 9.92 & 9.30 & 0.09 & 12.32 & 13.85 & 13.04 & 0.10 \\
\hline Mean aRPD (cm) & 6.35 & 7.80 & 7.19 & 0.08 & 7.59 & 8.75 & 8.35 & 0.07 \\
\hline Water column $\mathrm{O}_{2}$ status & - & - & Oxic & - & - & - & Oxic & - \\
\hline Methane bubbles & - & - & No & - & - & - & No & - \\
\hline No. mud clasts & 0.00 & 0.00 & 0.00 & - & 0.00 & 0.00 & 0.00 & - \\
\hline Epifauna visible & - & - & Some & - & - & - & Some & - \\
\hline Surface faecal pellet layer & - & - & No & - & - & - & Some & - \\
\hline Total no. surface tubes & 0.00 & 2.00 & 1.08 & 0.17 & 0.00 & 2.00 & 0.16 & 0.15 \\
\hline No. surface tubes $<2 \mathrm{~mm}$ & 0.00 & 0.00 & 0.00 & - & 0.00 & 2.00 & 0.16 & 0.15 \\
\hline No. surface tubes $>2 \mathrm{~mm}$ & 0.00 & 2.00 & 1.10 & 0.18 & 0.00 & 0.00 & 0.00 & - \\
\hline No. feeding mounds & 0.00 & 6.00 & 1.23 & 0.51 & 0.00 & 5.00 & 0.90 & 0.40 \\
\hline No. feeding pits & 0.00 & 0.00 & 0.00 & - & 0.00 & 0.00 & 0.00 & - \\
\hline Subsurface infauna & - & - & Yes & - & - & - & Yes & - \\
\hline No. subsurface burrows & 0.00 & 7.00 & 3.69 & 0.47 & 2.00 & 8.00 & 5.55 & 0.51 \\
\hline Subsurface oxic voids $<5 \mathrm{~cm}$ & - & - & No & - & - & - & No & - \\
\hline Subsurface oxic voids > $5 \mathrm{~cm}$ & - & - & Yes & - & - & - & Yes & - \\
\hline OSI score & 9.00 & 11.00 & 10.13 & 0.28 & 9.00 & 11.00 & 9.73 & 0.27 \\
\hline BHQ score & 6.00 & 14.00 & 11.10 & 0.65 & 9.00 & 14.00 & 10.90 & 0.40 \\
\hline
\end{tabular}

variation over the course of each deployment. There was no evidence of methane gas in the sedimentary matrix or water column hypoxia/anoxia. Despite visible bioturbatory action, mud clasts were not ejected onto the sediment-water interface.

The sediment appeared to be largely composed of brown-green muddy-sand deposits. In both image sequences, the overlying water column appeared to be non-turbid during all stages of the tidal cycle. On both occasions, the classification of the sediment particle size distribution indicated that fine sand ( 2 to $3 \phi$ or 250 to $125 \mu \mathrm{m}$ ) formed the bulk of the major modal fractions (Table 2). The particle size modal fractions did not vary with time and ranged from $>4 \phi$ to $1-2 \phi$ $(<63$ to $500 \mu \mathrm{m})$ during the neap tides and from 3-4 $\phi$ to $1-2 \phi$ (63 to $500 \mu \mathrm{m}$ ) during the spring tides.

As prism penetration was determined by the manual placement of the t-SPI module it did not reflect the relative compactness of the sediment. Prism penetration depth showed evidence of variation, ranging from 18.31 to $21.01 \mathrm{~cm}$ over the neap tidal cycles and from 17.05 to $19.53 \mathrm{~cm}$ over the spring tidal cycles (Table 2). This variation (see Figs. 4 \& 5) is attributed to the bioturbatory activities of Amphiura filiformis and Necora puber and reflects an increase in surface boundary roughness over the course of both t-SPI deployments.
Maximal variation in surface boundary roughness tended to coincide with the presence of a crab. Surface boundary roughness (i.e. maximum minus minimum depth of penetration) ranged from 0.10 to $2.09 \mathrm{~cm}$ during the neap tidal cycles and from 0.76 to $2.37 \mathrm{~cm}$ during the spring tidal cycles (Table 2).

The depth of the aRPD appeared to vary with time, an artefact caused by variations in prism penetration and surface boundary roughness. Mean aRPD depth ranged from 6.35 to $7.80 \mathrm{~cm}$ during the neap tides and from 7.59 to $8.75 \mathrm{~cm}$ during the spring tides (Table 2). These values represent an apparent sediment oxidised area that ranged from 95.30 to $116.95 \mathrm{~cm}^{2}$ and from 113.90 to $131.20 \mathrm{~cm}^{2}$ respectively (Table 2). Maximal aRPD depth ranged from 8.52 to $9.92 \mathrm{~cm}$ for the neap tides sequence and from 12.32 to $13.85 \mathrm{~cm}$ for the spring tides sequence (Table 2). The latter of these corresponded to an atypical vertical zone of high reflective sediment that penetrated deeper than the surrounding aRPD transition (Fig. 5). Minimal aRPD depth ranged from 3.81 to $6.16 \mathrm{~cm}$ for the neap tides and from 4.24 to $5.98 \mathrm{~cm}$ during the spring tides. The fluctuations in aRPD were never sufficient to alter the successional staging of the station.

The occurrence of surface mounds was directly related to the feeding activity of Amphiura filiformis, 

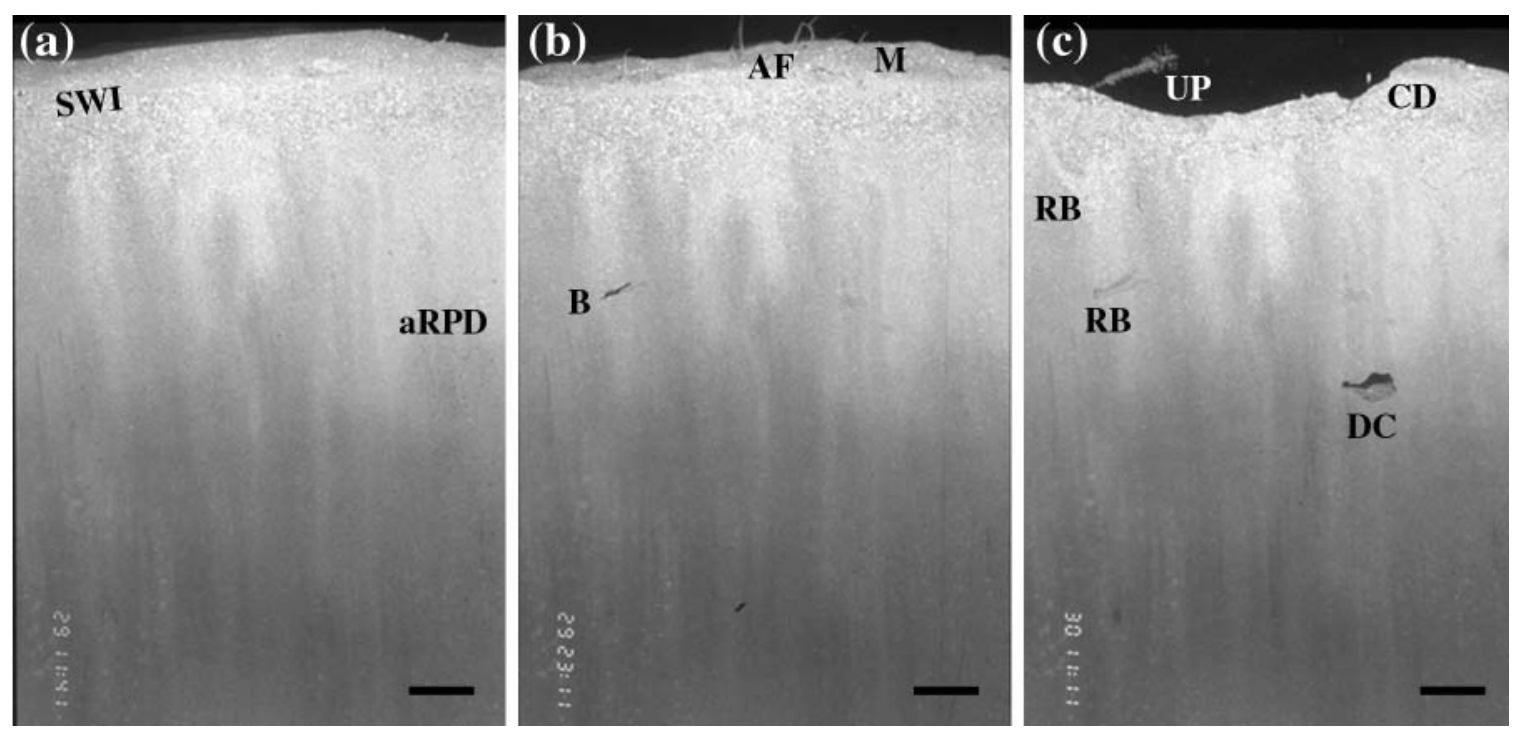

Fig. 4. Selected images from the neap tide in situ t-SPI occupation at Margaretta detailing (a) frame 0 (0 h), (b) frame 24 (12 h), and (c) frame $48(23.5 \mathrm{~h})$. The first image identifies the location of the sediment-water interface (SWI) and apparent redox potential discontinuity (aRPD) transition. The second and third images identify feeding arms of the ophiuroid Amphiura filiformis (AF) and mounds (M) associated with feeding activity. A. filiformis burrows (B), relict burrows (RB), and a disc chamber (DC) are indicated. The presence of an unidentified polychaete (UP) and surface crab disturbance (CD) are also noted. Scale bars $=2 \mathrm{~cm}$
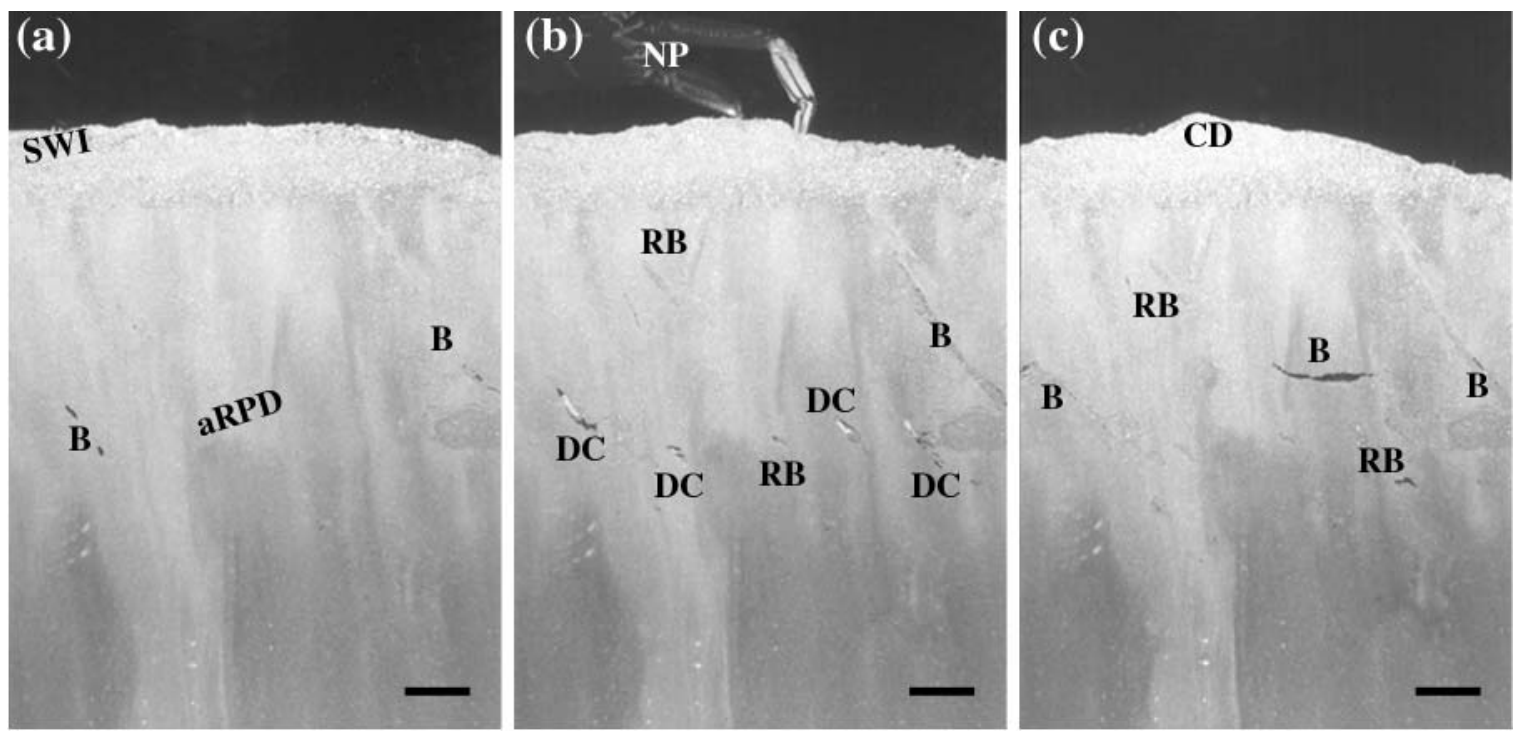

\section{RB}
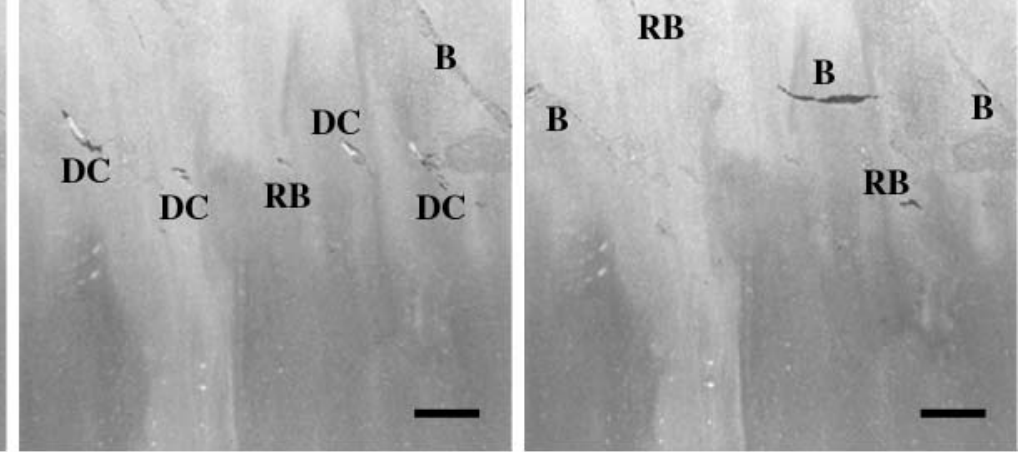

Fig. 5. Selected images from the spring tide in situ t-SPI occupation at Margaretta detailing (a) frame 0 (0 h), (b) frame 24 (12 h), and (c) frame $49(24 \mathrm{~h})$. The first image identifies the location of the sediment-water interface (SWI) and apparent redox potential discontinuity (aRPD) transition. Amphiura filiformis burrows (B), relict burrows (RB), and occupied disc chambers (DC) are indicated. The presence of a swimming crab, Necora puber (NP), and the associated surface crab disturbance (CD) are also noted.

Scale bars $=2 \mathrm{~cm}$

which mainly occurred during successive peak tidal flows (Fig. 6). Elevation of each 'arm' to the feeding position pushed particles to the sediment surface. The orientation of the disc required during feeding resulted in the individual moving into the uppermost area of the disc chamber, but not into the 'arm' shafts. The number of feeding mounds that occurred simultaneously in an image ranged from 0 to 6 during the neap tides and from 0 to 5 during the spring tides (Table 2). Voids were present at depth (i.e. $>5 \mathrm{~cm}$ ) 

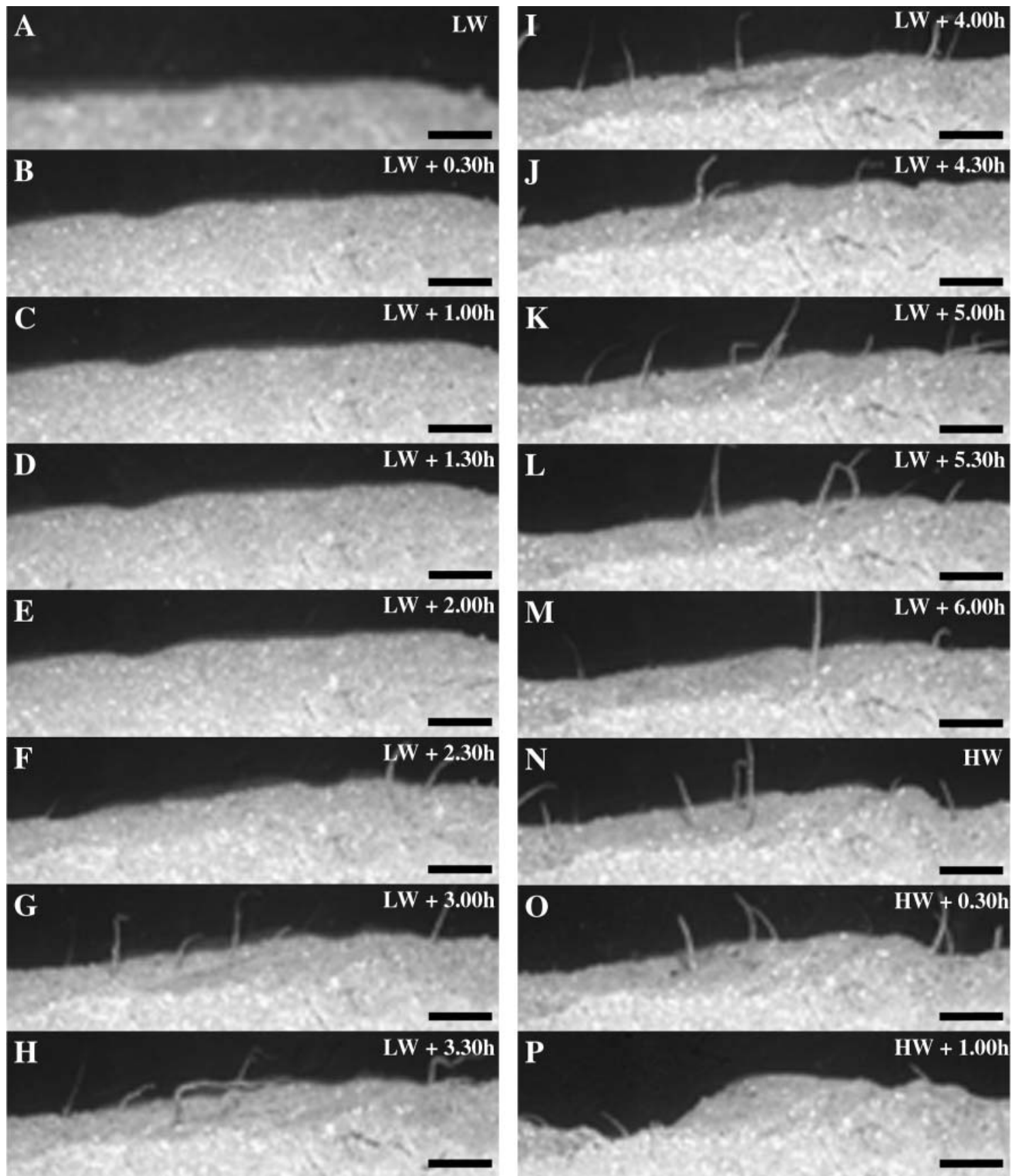

Fig. 6. Amphiura filiformis. Number of visible suspension feeding 'arms' over time during the spring tide t-SPI deployment. The timing of low water $(\mathrm{LW})$ and high water $(\mathrm{HW})$, in accordance with Admiralty charts, is also indicated. The image sequence (i.e. A to P) represents a $30 \mathrm{~min}$ increment since the previous image. Images have been cropped. Scale bars $=1 \mathrm{~cm}$

during both tides, but were more numerous in the spring tide sequence (e.g. Figs. 4 \& 5). Voids were constructed by Amphiura and constituted the disc chamber of the burrow structure. The disc chamber was occupied for extended periods of time while the organism was not feeding or maintaining the integrity of the burrow.
Manual insertion of the SPI camera assembly was sufficient to allow the calculation of the OSI and BHQ indices for all image replicates of each sequence. Both indices were sensitive to the changes that occurred throughout the time-lapse sequence. The OSI scores ranged from 9 to 11 during both t-SPI deployments (Table 2). The highest OSI scores (i.e. 11) occurred dur- 


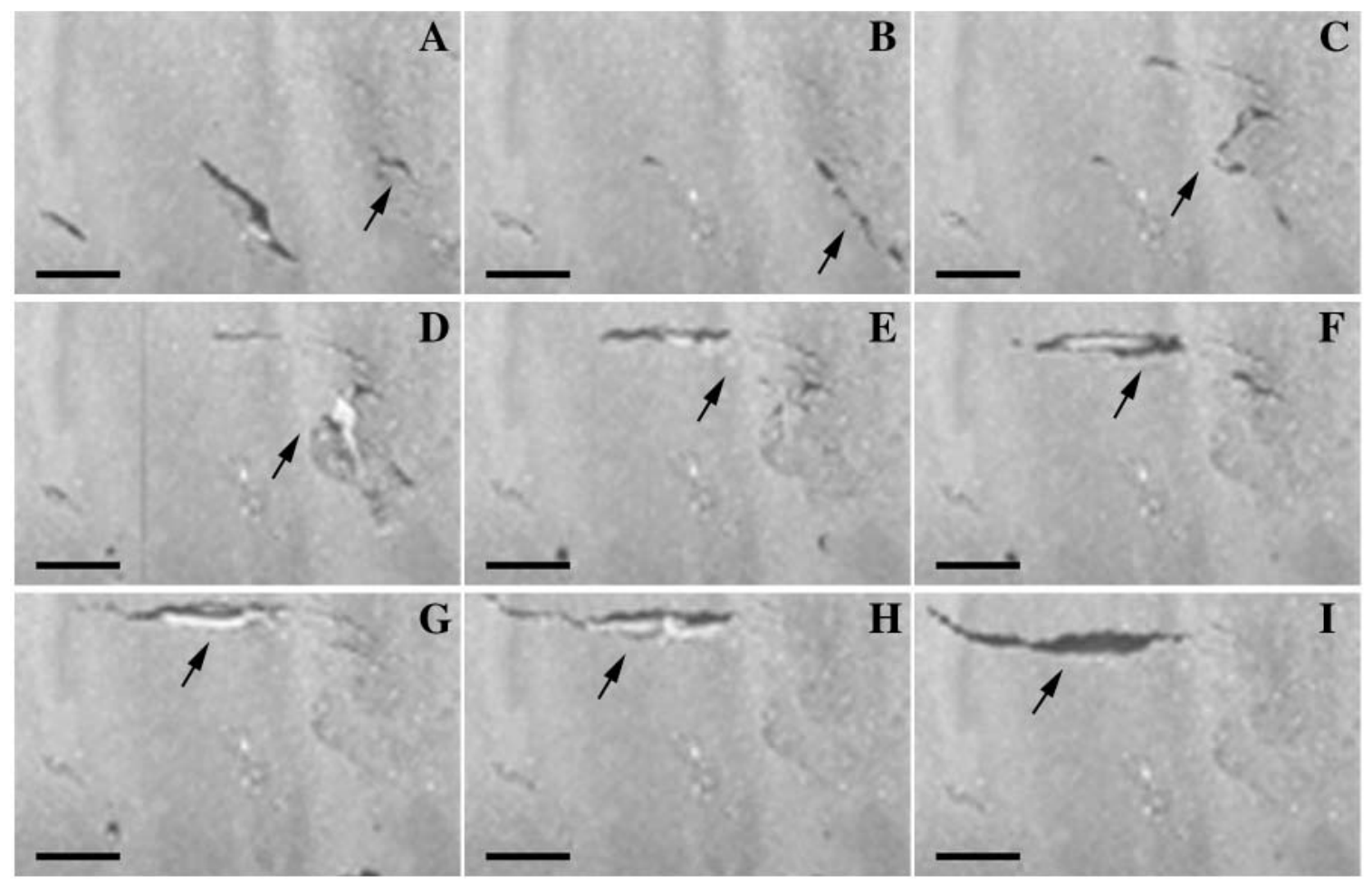

Fig. 7. Amphiura filiformis. Movement of one individual (Individual G) during the spring tide t-SPI occupancy. Arrows indicate the location of the burrow formation and each image represents a $30 \mathrm{~min}$ increment since the previous image. Scale bars $=1 \mathrm{~cm}$

ing the latter phase of the neap tides and the initial phase of the spring tides. The successional stage assigned to these scores suggests a high stage III status for both tides. Similarly, the BHQ scores ranged from 6 to 14 during the neap tides and from 9 to 14 during the spring

Table 3. Summary information for the apparent spatial arrangement of 8 individual Amphiura filiformis excavations (Excavations A to $\mathrm{H}$, see Fig. 3) observed during the spring tide t-SPI deployment. Data are presented for the maximum depth and angle of each excavation and the linear distance to the nearest adjacent excavation. The mean and 95\% confidence limits $(n=8)$ for these data are presented

\begin{tabular}{|cccc|}
\hline Burrow & $\begin{array}{c}\text { Maximum } \\
\text { depth } \\
(\mathrm{cm})\end{array}$ & $\begin{array}{c}\text { Angle from } \\
\text { horizontal } \\
\left({ }^{\circ}\right)\end{array}$ & $\begin{array}{r}\text { Distance to } \\
\text { nearest exca- } \\
\text { vation }(\mathrm{cm})\end{array}$ \\
\hline A & 11.73 & 54.80 & 2.14 \\
B & 6.25 & 66.30 & 1.11 \\
C & 10.24 & 40.30 & 2.14 \\
D & 6.72 & 52.00 & 1.11 \\
E & 9.73 & 37.20 & 1.71 \\
F & 9.48 & 46.90 & 1.41 \\
G & 9.99 & 51.40 & 1.41 \\
H & 7.48 & 54.70 & 2.12 \\
Mean & 8.95 & 50.45 & 1.64 \\
$95 \%$ CI & 1.6 & 7.63 & 0.37 \\
\hline
\end{tabular}

tides (Table 2). The highest BHQ scores (i.e. 14) occurred in the latter phase of the neap tides and the initial phases of the spring tides. The successional stage assigned to these scores also suggests a high stage 3 for both tides.

\section{Time-lapse animal-sediment relations}

A total of 8 individual Amphiura filiformis excavations (i.e. Excavations A to $\mathrm{H}_{\text {; }}$ Fig. 3) were visible against the camera face-plate for extended periods of time through the spring tide. The apparent depth of these excavations continually oscillated, with the maximum depth (Table 3) attained over the $24 \mathrm{~h}$ period ranging from $6.25 \mathrm{~cm}$ (Excavation $\mathrm{B}$ ) to $11.73 \mathrm{~cm}$ (Excavation A). Apparent mean maximum excavation depth $( \pm 95 \% \mathrm{CI}, \mathrm{n}=8)$ was $8.95 \pm 1.6 \mathrm{~cm}$ (Table 3$)$. The angle of each excavation from the horizontal plane of the sediment-water interface ranged from $37.20^{\circ}$ (Excavation E) to $66.30^{\circ}$ (Excavation B), giving a mean $( \pm 95 \%$ $\mathrm{CI}, \mathrm{n}=8$ ) apparent orientation of $50.45 \pm 7.63^{\circ}$ (Table $3)$. This appeared to be independent of excavation depth and did not reflect the spatial arrangement of feeding arms during feeding activity. The shortest linear distance to the nearest excavation ranged from $1.11 \mathrm{~cm}$ (Excavations B and D) to $2.14 \mathrm{~cm}$ (Excavations 

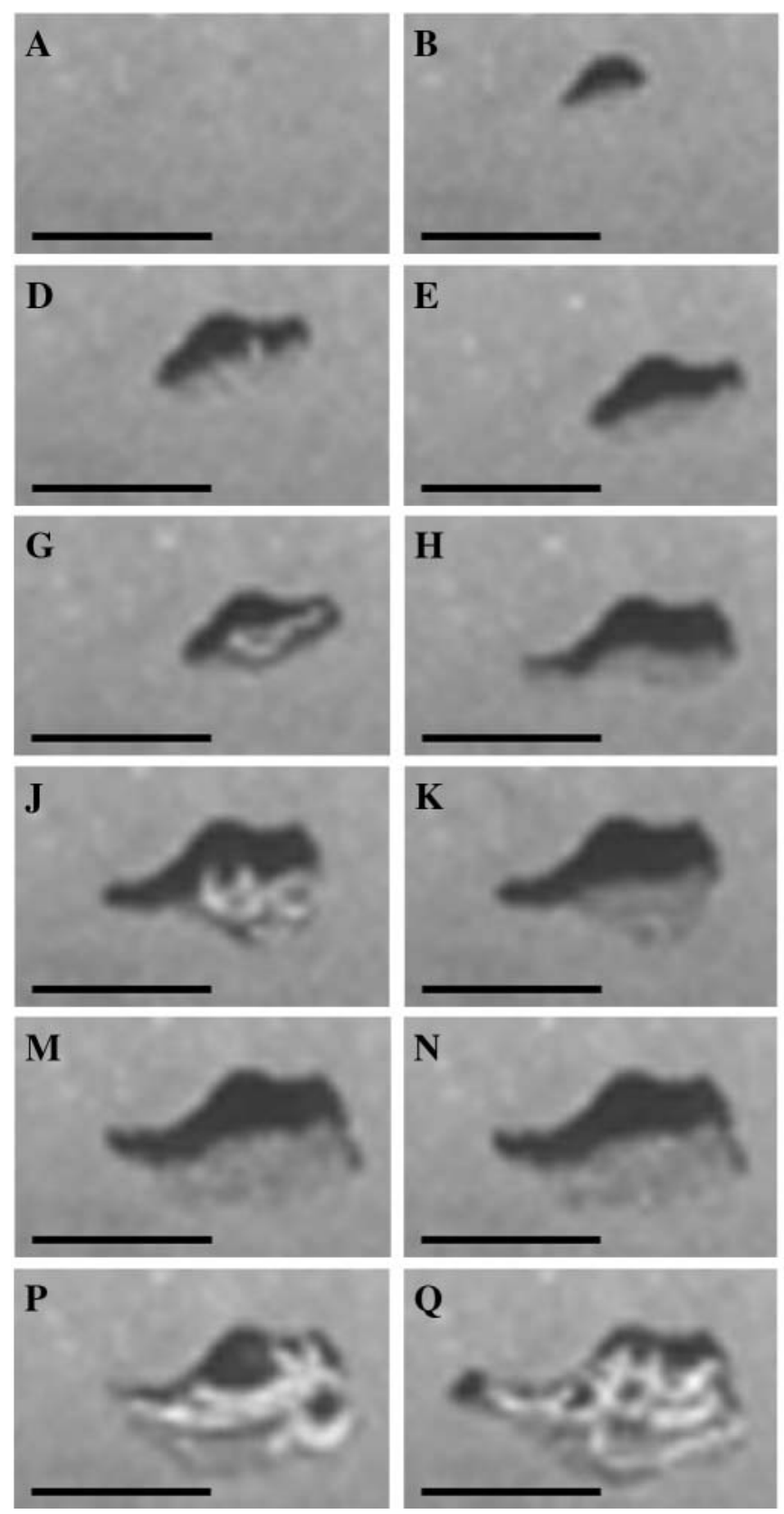
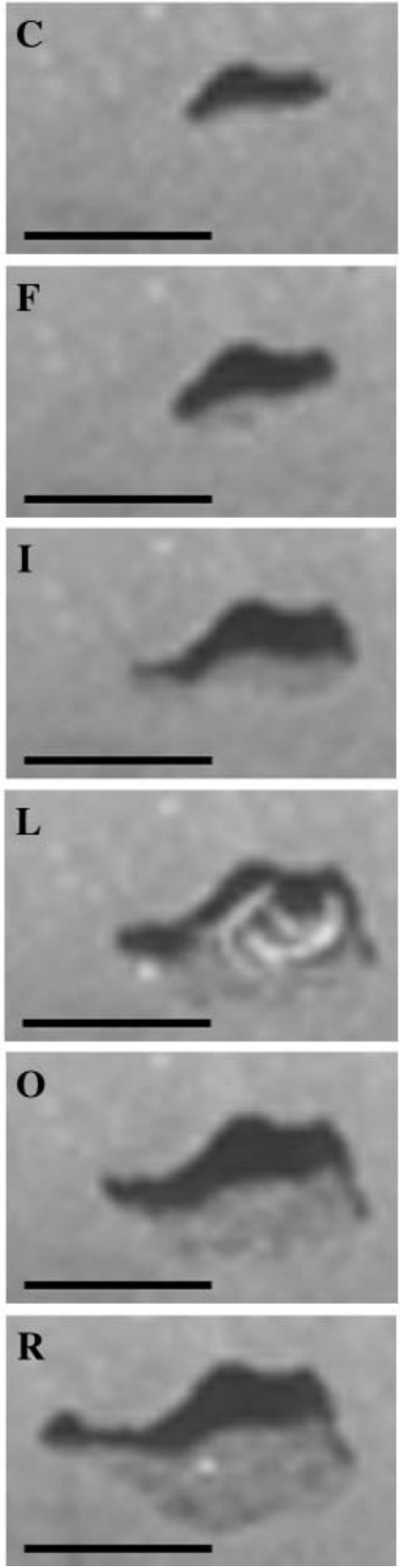

Fig. 8. Amphiura filiformis. Sequence of images (i.e. A to R) used for calculation of the apparent equivalent half spherical volume of a disc chamber for 1 individual during the neap tide t-SPI occupancy. Each image represents a $30 \mathrm{~min}$ increment since the previous image. Scale bars $=1 \mathrm{~cm}$
A and C) representing a mean $( \pm 95 \%$ CI $)$ apparent spacing of $1.64 \pm 0.37 \mathrm{~cm}$ (Table 3 ).

The apparent rate of burrowing, burrow infill, and the net creation of new void for a non-stationary (i.e. excavation relocation) individual of Amphiura filiformis was extrapolated from the movement of Individual G (Fig. 3) during a $4 \mathrm{~h}$ period of the spring tide sequence (Fig. 7). During this time, Individual $\mathrm{G}$ moved an apparent linear distance of $5.76 \mathrm{~cm}$ (i.e. $1.44 \mathrm{~cm} \mathrm{~h}^{-1}$ ) and excavated $0.179 \mathrm{~cm}^{3}$ of sediment. A total of $0.147 \mathrm{~cm}^{3}$ of sediment infilled behind the organism as it moved forwards, producing a net apparent void of $0.032 \mathrm{~cm}^{3}$ (i.e. $0.008 \mathrm{~cm}^{3} \mathrm{~h}^{-1}$ ).
The apparent maximum volume and rate of disc chamber formation was estimated from one individual of Amphiura filiformis during the neap tides occupancy. The disc chamber was located at $9.15 \mathrm{~cm}$ depth and was monitored for $7.5 \mathrm{~h}$ (Fig. 8). Construction of the disc chamber appeared to occur in activity bouts of approximately $2 \mathrm{~h}$, interspersed by apparent rest periods of similar duration (Fig. 9). Maximum apparent disc chamber volume was $0.27 \mathrm{~cm}^{3}$ after $7 \mathrm{~h}$.

Feeding activity of the resident Amphiura filiformis population throughout the spring tides appeared to be related to current speed. In the latter stages of 


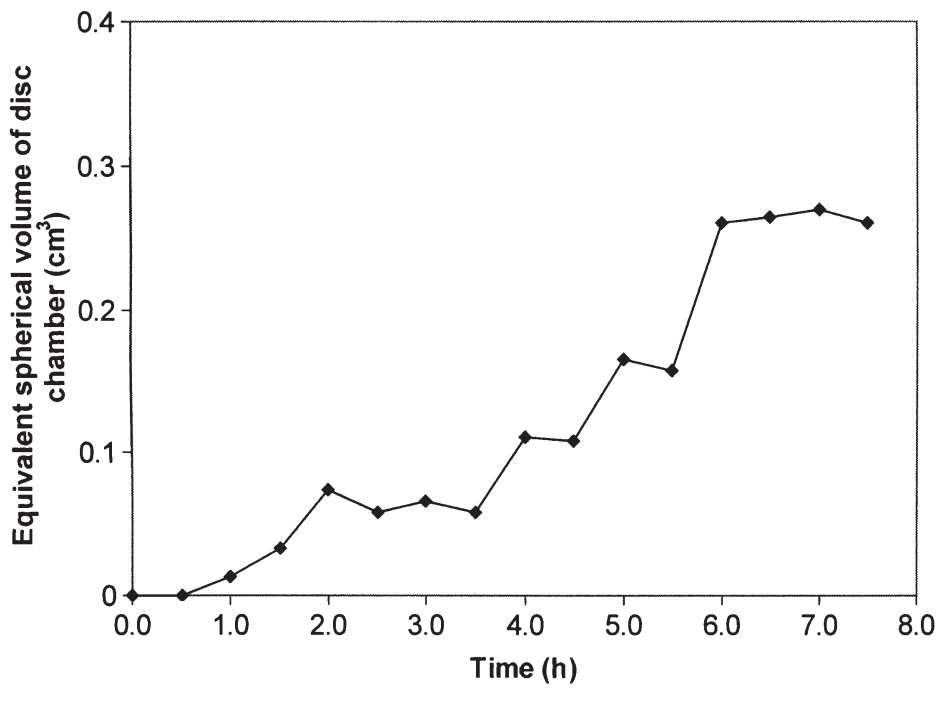

Fig. 9. Amphiura filiformis. The apparent equivalent half spherical volume of a disc chamber for 1 individual monitored for $7.5 \mathrm{~h}$ during the neap tide t-SPI occupancy

deployment, aggregation of an unknown number of swimming crabs Necora puber around the camera assembly disrupted the sediment surface causing the retraction of feeding 'arms'. A visible crab presence occurred at $7 \mathrm{~h}$ (frame 15), $11.5 \mathrm{~h}$ (frame 24), and $20.5 \mathrm{~h}$ (frame 42) following the start of the sequence. It is speculated that such crab activity continued from $11 \mathrm{~h}$ to the end of the deployment and negatively influenced the feeding activities of the local $A$. filiformis population. Nevertheless, suspension feeding activity by $A$. filiformis commenced at approximately 1 to $2 \mathrm{~h}$ following high or low tide, peaked during the midtide, and ended at approximately 1 to $2 \mathrm{~h}$ before the next tide (Fig. 6). The largest number of active feeding 'arms' (approximately 25 to 35) occurred 2 to $6 \mathrm{~h}$ after the first high tide. The lowest number $(<5)$ of active feeding 'arms' occurred 1 to $12 \mathrm{~h}$ after the second high tide. During slack tidal periods, individuals remained below the sediment surface and either rested (i.e. arms largely retracted in the disc chamber) or maintained the integrity of the burrow structure (i.e. arms just short of the sediment-water interface). As the apparent current regime increased, the number of suspension feeding 'arms' present at the surface gradually increased. In apparent low current regimes $(<3 \mathrm{~h}$ post tide), feeding 'arms' were positioned vertically and extended $>20 \mathrm{~mm}$ into the overlying water column (Fig. 6, frames L to O). As current flow continued to increase, the tips of the feeding 'arms' first kinked (Fig. 6, frame G) and proceeded to adopt an inverted L shaped posture (Fig. 6, frame H). The same sequence of events took place in reverse following peak tidal flow.
The ejection of sediment to the surface associated with the feeding activity of Amphiura filiformis was estimated from 5 mounds visible during the spring tide t-SPI occupation. These mounds were visible over a period of $12 \mathrm{~h}$, but not always simultaneously. The apparent rate of mound construction and disintegration varied in accordance with the vertical extension of the feeding 'arm' and water current erosion. The passage of a number of swimming crabs (Necora puber) was responsible for destroying some mound structures. The maximum apparent volume of the mounds (Fig. 2) ranged from $0.16 \mathrm{~cm}^{3}$ (Mound 1) to $1.30 \mathrm{~cm}^{3}$ (Mound 5), giving a mean maximal mound volume $( \pm 95 \% \mathrm{CI}$, $\mathrm{n}=5$ ) of $0.60 \pm 0.54 \mathrm{~cm}^{3}$. Sediment ejected to the surface during the formation of each mound appeared to be oxidised and originated from above the aRPD, mainly from the re-clearance of 'arm' burrows.

The total surface area of an individual Amphiura filiformis excavation (assuming 1 arm burrow and 1 disc chamber) was estimated using measurements obtained from both the neap and the spring tide t-SPI deployments. Assuming that each burrow is identical, with 1 arm burrow $(8.95 \mathrm{~cm}$ long and $0.23 \mathrm{~cm}$ wide) terminating in a disc chamber (with a volume of $0.27 \mathrm{~cm}^{3}$ ), the total surface area of one $A$. filiformis excavation amounts to $8.98 \mathrm{~cm}^{2}$. This figure, however, is a conservative estimate of the total surface area that may be expected for a complete $A$. filiformis excavation, as it is known that $A$. filiformis ordinarily extends at least 2 'arms' from the disc chamber. The addition of 2 more 'arm' burrows to the previous estimate increases the surface area for each excavation to $22.14 \mathrm{~cm}^{2}$.

\section{DISCUSSION}

The images obtained in this study show a number of features, such as a highly reworked sediment profile and a deep aRPD, typical of an advanced successional assemblage. These factors are reflected in the high OSI and BHQ scores (i.e. stage III, sensu Rhoads \& Germano 1982) obtained throughout each deployment sequence. There can be little doubt that the majority of these features are a product of the ophiuroid Amphiura filiformis, known to occur in high densities (>700 ind. $\mathrm{m}^{-2}$ ) at this station (O'Connor et al. 1983, 1986a, 1986b, Kennedy 2000, Solan 2000). Indeed, the use of t-SPI revealed an unprecedented amount of information relating to the feeding and burrowing behaviour of this organism and visually demonstrated the mechanics and extent of biogenic influence that this species has on the sediment stratigraphy. 
Of particular importance in determining the physical structure of the sediment are the excavations made by Amphiura filiformis. During the course of the t-SPI deployments, A. filiformis constructed and inhabited a number of burrows that extended several $\mathrm{cm}$ into the sediment profile. These structures were remarkably consistent in terms of size, shape and positioning and represent a significant increase in the surface area (ca. $20 \mathrm{~cm}^{2}$ ind. ${ }^{-1}$ ) available for oxygenic decomposition over that of an azoic sediment. Densities of $A$. filiformis are known to exceed 3000 ind. $\mathrm{m}^{-2}$ (Josefson 1995) although for Galway Bay 700 ind. $\mathrm{m}^{-2}$ is a more appropriate estimate (O'Connor et al. 1986b). A population of $A$. filiformis at this latter density may expose $1.4 \mathrm{~m}^{2}$ of burrow wall per $\mathrm{m}^{2}$ of sediment surface. Each excavation consisted of a number of feeding 'arm' conduits that connected the surface to a disc chamber located at approximately 6 to $10 \mathrm{~cm}$ depth. Construction of these chambers appears to involve regular bouts of activity interspersed by apparent periods of rest over a number of hours. Once complete, individuals continually maintain the integrity of the burrow or are involved in feeding-related activity. Burrow preservation appeared to involve repeated journeys along the excavation, and the spatial distance between burrows (ca. $1.64 \mathrm{~cm}$ ) appeared to be actively maintained. An encounter between 2 individuals resulted in the relocation of at least 1 burrow suggesting that the dispersion of $A$. filiformis individuals is density-dependent (Rosenberg et al. 1997). The repositioning of Individual G indicated that these movements are slow (ca. $1.44 \mathrm{~cm} \mathrm{~h}^{-1}$ ) and involve the displacement of large volumes of sediment relative to the creation of new void. Such continuous movement and biological modification of the sedimentary fabric must have a significant impact on the bulk density and stability of the sediment profile, facilitating the penetration of oxidised water and the depression of the aRPD. These changes will impact on the magnitude and rate of biogeochemical cycling and may influence micro-, meio- and macrobenthic community structure. This assumption would seem appropriate given the similarity in depth of the aRPD and disc chamber structures, the highly reworked upper sediment profile, and the mounding of surface sediment. These factors presumably facilitate the degradation of labile organic matter through the exposure of reduced sub-surface sediment to oxygenated water and contribute to the maintenance of a high successional assemblage (Kristensen 2000).

The in situ t-SPI observations of feeding behaviour in Amphiura filiformis confirm the laboratory findings of Buchanan (1964) and Woodley (1975) who showed that feeding activity is related to the strength and direction of water currents. At slack tide, individuals show little evidence of suspension feeding activity and the 'arms' remain within the confines of the burrow structure. As current speed fluctuates either side of mid-tide, the orientation of each feeding 'arm' follows a predictable morphological sequence that may serve to maximise particle capture and retention rates in varying flow regimes (Loo et al. 1996). This mechanism appears to occur simultaneously throughout the population and presumably provides a significant pathway for the direct import of organic material deep into the sediment profile.

The extension of Amphiura filiformis 'arms' into the overlying water column during feeding is also known to be a source of food to many fish and invertebrate predators (e.g. van Duineveld \& Noort 1986, Baden et al. 1990). Such 'sub-lethal' cropping is a common occurrence and subsequent regenerative growth may significantly contribute to the total annual production of the population (Bowmer \& Keegan 1983, Sköld et al. 1994, Rosenberg \& Selander 2000). The aggregation of a number of swimming crabs (i.e. Necora puber) around the camera assembly during bouts of suspension feeding activity appeared to elicit a predation avoidance response throughout the local A. filiformis population. When subjected to a disturbance from above, individuals immediately retracted to the safety of their burrows for extended periods of time, even in times of peak feeding potential. It is likely that the observed behaviour was initially in response to tactile stimuli rather than the recognition of a predator species, and then propagated through the population by some other mechanism such as chemoreception (Rosenberg \& Selander 2000). Despite an extensive disruption to feeding activity by a number of crabs, the activity associated with feeding resulted in a significant increase in surface boundary roughness through the production of pits and mounds on the sediment surface. The ejection of material to the sediment surface occurs as each active feeding 'arm' pushes up through the sediment-water interface into the overlying water column. The upward and downward movement of 'arms' associated with feeding also resulted in a reorientation of the disc in the disc chamber, but disc movements did not result in the displacement of sediment. The present study suggests that each mound forms rapidly and may have a volume in excess of $1 \mathrm{~cm}^{3}$. Given that $A$. filiformis is known to employ at least 2 'arms' during feeding and can reach densities in excess of 3000 ind. $\mathrm{m}^{-2}$, the volume of sediment cycled in this way is potentially enormous and has a considerable impact on the mass properties of the sediment.

The results obtained using t-SPI indicate that Amphiura filiformis is rarely stationary and its continuous bioturbatory activities associated with burrowing and feeding have a significant impact on the sediment fabric. Although many species present in an Amphiura- 
Echinocardium assemblage are capable of influencing the physical nature of the sediment, the presence of $A$. filiformis in high abundance seems to be of particular structural importance. Indeed, many of the features witnessed in the t-SPI sequences can be directly linked to the actions of $A$. filiformis. In this regard, A. filiformis may be seen as a 'structural engineer' responsible for the visual features of the sediment profile, a conclusion consistent with the findings of $\mathrm{O}^{\prime}$ Connor et al. (1983) and Rowden et al. (1998). However, it would be incorrect to conclude solely on this basis that the presence of Amphiura is responsible for assemblage structure. The bioturbatory signatures of other organisms belonging to this assemblage are not apparent, yet many other species (e.g. Pholoe inornata, Nephtys hombergii, Lumbrineris fragilis, Mysella bidentata, Thyasira flexuosa) are known to occur in high densities and/or have a significant impact on the sediment fabric (e.g. Echinocardium cordatum, Corystes cassivelaunus). We contend that the evidence of sediment reworking by these and other species is masked by the continuous activity of $A$. filiformis and may therefore be underestimated. Further work of this type is required to understand the dynamic processes and events that structure benthic communities and to establish the relative roles of individual species in isolation and in mixture.

Acknowledgements. A copy of the t-SPI movies can be obtained from the authors on request. This work was funded by the E.U. under the 'MAST III-Marine Science and Technologies' programme (Contract No. MAS3-CT96-5035), and also by the Benthos Research Group (Head: Prof. Brendan Keegan), Department of Zoology, National University of Ireland, Galway. We thank Albert Lawless, John Galvin and Eamonn Kelly for scuba diving. Technical assistance and loan of equipment from Aquafact International Services Ltd., Galway, Ireland, and also Sea Sense Ltd., Galway, Ireland, is gratefully acknowledged.

\section{LITERATURE CITED}

Baden SP, Pihl L, Rosenberg R (1990) Effects of oxygen depletion on the ecology, blood physiology and fishery of the Norway lobster Nephrops norvegicus. Mar Ecol Prog Ser 67:141-155

Bett BJ, Rice AL (1993) The feeding behaviour of an abyssal echiuran revealed by in situ time-lapse photography. Deep-Sea Res I 40(9):1767-1779

Booth DA (1975) The water structure and circulation of Killary Harbour and of Galway Bay. PhD thesis, National University of Ireland, Galway

Bowmer T (1982) Reproduction in Amphiura filiformis (Echinodermata: Ophiuroidea): seasonality in gonad development. Mar Biol 69:281-290

Bowmer T, Keegan BF (1983) Field survey of the occurrence and significance of regeneration in Amphiura filiformis (Echinodermata: Ophiuroidea) from Galway Bay, west coast of Ireland. Mar Biol 74:65-71

Buchanan JB (1964) A comparative study of some features of the biology of Amphiura filiformis and Amphiura chiajei
(Ophiuroidea) considered in relation to their distribution. J Mar Biol Assoc 44:565-576

Collins MA, Priede IG, Addison S, Smith A, Bagley PM (1998) Acoustic tracking of the dispersal of organic matter by scavenging fishes in the deep sea. Hydrobiologia 371/372: 181-186

Diaz RJ, Cutter GR Jr (in press) In situ measurement of organism-sediment interaction: rates of burrow formation/abandonment and sediment oxidation/reduction. In: Aller JY, Woodin SA, Aller RC (eds) Organism-sediment interactions. Belle W. Baruch Library in Marine Science, University of South Carolina Press, Columbia, SC

Diaz RJ, Schaffner LC (1988) Comparison of sediment landscapes in Chesapeake Bay as seen by surface and profile imaging. In: Lynch MP, Krome EC (eds) Understanding the estuary: advances in Chesapeake Bay research. Publication 129, CBP/TRS 24/88. Chesapeake Research Consortium, Solomons, MD, p 222-240

Harte AM, Gilroy JP, McNamara SF (1982) A computer simulation of water circulation in Galway Bay. Engineering $\mathrm{J}$ 35:6-7

Josefson AB (1995) Large-scale estimate of somatic growth in Amphiura filiformis (Echinodermata: Ophiuroidea). Mar Biol 124:435-442

Keegan BF, Retière C (1987) Marine pollution: environmental monitoring of soft sea floors by means of electronic imaging of the sediment profile. Summary report on Contract No. B-04-08, Commission of the European Communities, Brussels

Keegan BF, O'Connor B, McGrath D, Konnecker G (1976) The Amphiura filiformis-Amphiura chiajei community in Galway bay (West coast of Ireland) - a preliminary account. Thalassia Jugoslavica 12:189-198

Kennedy R (2000) Animal-sediment relations in Inner Galway Bay, west coast of Ireland, with particular reference to bioturbation. PhD thesis, National University of Ireland, Galway

Kristensen E (2000) Organic matter diagenesis at the oxic/ anoxic interface in coastal marine sediments, with emphasis on the role of burrowing animals. Hydrobiologia 426: $1-24$

Lei W (1995) Three-dimensional hydrodynamic modelling in Galway Bay. PhD thesis, National University of Ireland, Galway

London GD, Bauman KL, Asa CS (1998) Time-lapse infrared videography for animal behaviour observations. Zoo Biol 17:535-543

Loo LO, Jonsson PR, Sköld M, Karlsson Ö (1996) Passive suspension feeding in Amphiura filiformis (Echinodermata: Ophiuroidea): feeding behaviour in flume flow and potential feeding rate of field populations. Mar Ecol Prog Ser 139:143-155

Nestlerode JA, Diaz RJ (1998) Effects of periodic environmental hypoxia on predation of a tethered polychaete, Glycera americana: implications for trophic dynamics. Mar Ecol Prog Ser 172:185-195

Ni Cheileachair O (1992) Organic enrichment in Inner Galway Bay with particular reference to the macrobenthic infauna and associated sediments. MSc thesis, National University of Ireland, Galway

Nilsson HC, Rosenberg R (1997) Benthic habitat quality assessment of an oxygen stressed fjord by surface and sediment profile images. J Mar Syst 11:249 - 264

O'Connor B, Bowmer T, Grehan A (1983) Long-term assessment of the population dynamics of Amphiura filiformis (Echinodermata: Ophiuroidea) in Galway Bay (west coast of Ireland). Mar Biol 75:279-286 
O'Connor B, Bowmer T, McGrath D, Raine R (1986a) Energy flow through an Amphiura filiformis (Ophiuroidea: Echinodermata) population in Galway Bay, west coast of Ireland: A preliminary investigation. Ophelia 26:351-357

O'Connor BDS, McGrath D, Keegan BF (1986b) Demographic equilibrium: the case of an Amphiura filiformis assemblage on the west coast of Ireland. Hydrobiologia 142: 151-158

Pagnoni GA (1999) Disturbance and recruitment of Amphiura filiformis in Galway Bay (west of Ireland). Ital J Zool 66: $147-151$

Pearson TH, Rosenberg R (1976) A comparative study of the effects on the marine environment of wastes from cellulose industries in Scotland and Sweden. Ambio 5(2): 77-79

Pearson TH, Rosenberg R (1978) Macrobenthic succession in relation to organic enrichment and pollution of the marine environment. Oceanogr Mar Biol Annu Rev 16: 229-311

Rhoads DC, Cande S (1971) Sediment profile camera for in situ study of organism-sediment relations. Limnol Oceanogr 16:110-114

Rhoads DC, Germano JD (1982) Characterisation of organismsediment relations using sediment profile imaging: an efficient method of remote ecological monitoring of the seafloor (REMOTS ${ }^{\text {TM }}$ system). Mar Ecol Prog Ser 8:115-128

Rhoads DC, Germano JD (1986) Interpreting long-term changes in benthic community structure: a new protocol. Hydrobiologia 142:291-308

Rhoads DC, Young DK (1970) The influence of depositfeeding organisms on sediment stability and community trophic structure. J Mar Res 28(2):150-178

Rhoads DC, McCall PL, Yingst JY (1978) Disturbance and production on the estuarine seafloor. Am Sci 66:577-586

Rosenberg R (1976) Benthic faunal dynamics during succes-

Editorial responsibility: Otto Kinne (Editor),

Oldendorf/Luhe, Germany sion following pollution abatement in a Swedish estuary. Oikos 27:414-427

Rosenberg R, Selander E (2000) Alarm signal response in the brittle star Amphiura filiformis. Mar Biol 136:43-48

Rosenberg R, Nilsson HC, Hollertz K, Hellman B (1997) Density dependent migration in an Amphiura filiformis (Amphiuridae, Echinodermata) infaunal population. Mar Ecol Prog Ser 159:121-131

Rowden AA, Jago CF, Jones SE (1998) Influence of benthic macrofauna on the geotechnical and geophysical properties of surficial sediment, North Sea. Cont Shelf Res 18: $1347-1363$

Sköld M, Loo LO, Rosenberg R (1994) Production, dynamics and demography of an Amphiura filiformis population. Mar Ecol Prog Ser 103:81-90

Smith KL Jr, Kaufmann RS, Wakefield WW (1993) Mobile megafaunal activity monitored with a time-lapse camera in the abyssal North Pacific. Deep-Sea Res Part I 40(11/12): $2307-2324$

Solan M (2000) The concerted use of 'traditional' and Sediment Profile Imagery (SPI) methodologies in marine benthic characterisation and monitoring. PhD thesis, National University of Ireland, Galway

Tyler PA, Gage JD, Paterson GJL, Rice AL (1993) Dietary constraints on reproductive periodicity in two sympatric deepsea astropectinid seastars. Mar Biol 115:267-277

Valente RM, Rhoads DC, Germano JD, Cabelli VJ (1992) Mapping of benthic enrichment patterns in Narragansett Bay, RI Estuaries 15(1):1-17

van Duineveld GCA, Noort GJ (1986) Observations on the population dynamics of Amphiura filiformis (Ophiuroidea: Echinodermata) in the southern North Sea and exploitation by the Dab, Limanda limanda. Neth J Sea Res 20:85-94

Woodley JD (1975) The behaviour of some amphiurid brittlestars. J Exp Mar Biol Ecol 18:29-46

Submitted: January 8, 2001, Accepted: June 21, 2001

Proofs received from author(s): February 6, 2002 